\title{
Study of AlSi7Mg0.6 Alloy by Selective Laser Melting: Mechanical Properties, Microstructure, Heat Treatment
}

\author{
Arnold Mauduit* (D), Hervé Gransac, Pierre Auguste, Sébastien Pillot \\ CETIM Centre Val de Loire (CRAl: Centre de Référence de l'Aluminium - pole matériaux et procédés), 3-7 rue Charles de Bange, 18000 \\ Bourges, France \\ *e-mail: arnold.mauduit@cetimcentrevaldeloire.fr
}

Received: 1 February 2019/Accepted: 15 March 2019/Published online: 31 March 2019

This article is published with open access by AGH University of Science and Technology Press

\begin{abstract}
This study presents a panorama of the AlSi7Mg0.6 (A357) aluminum alloy in additive manufacturing by selective laser melting. The document is mainly interested in the metallurgical tempers obtained after manufacture and after heat treatment; it quickly cover the process. The results concerning the material integrity (porosity), mechanical properties, microstructures, residual stresses, etc., are presented in order to best define the technological capacities of these metallurgical tempers: as-built, soft annealed, T6, and artificial aging. Some information on the mechanisms and kinetics of precipitation is also presented using the Johnson-Mehl-Avrami-Kolmogorov model. Finally, the conclusion proposes an inventory (advantages/disadvantages) of the metallurgical tempers obtained to better understand the industrial applications.
\end{abstract}

\section{Keywords:}

AlSi7Mg0.6 (A357) alloy, selective laser melting, heat treatment (T6, soft annealing, artificial aging)

\section{INTRODUCTION}

Selective laser melting is an additive manufacturing technique. It is characterized by layer-by-layer construction of a part to be produced: a laser melts the metal powder according to the 3D data entered into a computer. This process is now well-known and documented [1].

The AlSi7Mg0.6 aluminum alloy was historically intended for sand or gravity die casting. Its chemical composition and mechanical properties are specified in the EN 1706: 2010 standard. This alloy is excellent for casting, and it possesses good corrosion resistance, good weldability, and good mechanical properties, which make it a reference for industrial sectors like aeronautics, automotive, and defense. In recent years, this alloy has been used in selective laser melting alongside the AlSi10Mg alloy, which was the first aluminum alloy to be implemented in laser melting. Today, AlSi10Mg is the reference aluminum alloy for selective laser melting [2]. With its silicon content, AlSi7Mg0.6 enables good implementation for laser melting; indeed, it prevents all phenomena of hot cracking that is in the form of interdendritic or intergranular cracking [3]. Several recent studies cover the implementation of AlSi7Mg0.6 (or A357) in laser melting. Most focus is on the powder, on the implementation parameters of the alloy that enable a sound part to be obtained with a minimum of porosity [4], but far fewer documents deal with the microstructure, mechanical properties, heat treatment, etc. Therefore, the study will quickly move on from obtaining and controlling the process parameters to expanding on the metallurgy achieved after laser melting as well as the heat treatment that can be used. Indeed, the main objective of this document is to be interested in the mechanical properties like UTS, YS, residual stresses, the metallurgical structures, and the heat treatment of the AlSi7Mg0.6 alloy resulting from selective laser melting.

\section{MATERIALS AND METHODS}

\subsection{Selective laser melting machine}

The machine used for this study is an SLM 280 HL (SLM Solutions) equipped with a $400 \mathrm{~W}$ YAG laser. The manufacturing plates are made of an aluminum alloy. The temperature of the manufacturing plate is $150^{\circ} \mathrm{C}$. All of the tests were carried out with gas shielding: argon with a minimum purity level of $99.99 \%$. The layer thickness is set to $50 \mu \mathrm{m}$, the laser power to $350 \mathrm{~W}$, and the scan speed 
to $920 \mathrm{~mm} / \mathrm{s}$. The manufacturing strategy used is known as "banding," with layers crossed at $90^{\circ}$ to the others (the first layer marked with red lines, followed by the second layer marked with green lines). This is shown in Figure 1.

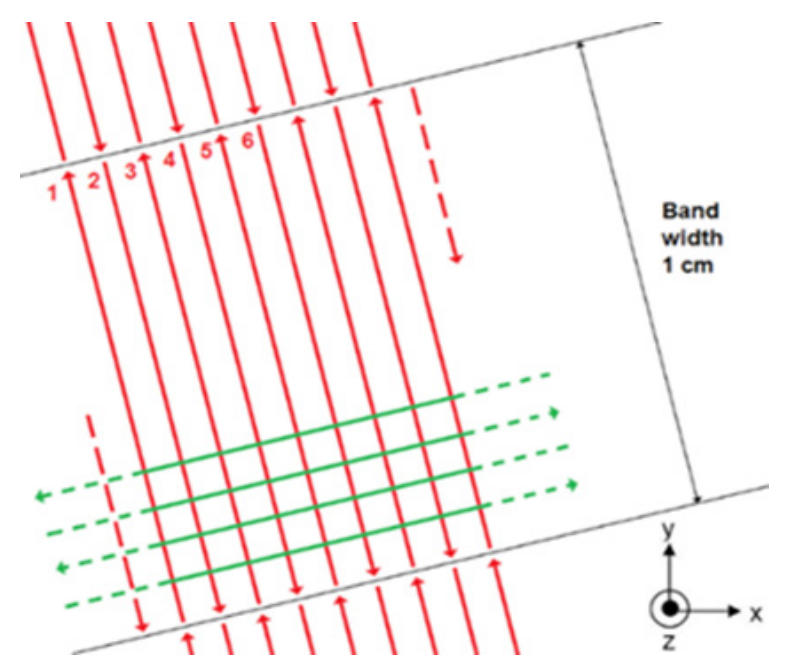

Fig. 1. "Banding” manufacturing strategy

\subsection{Powders and test pieces}

The AlSi7Mg0.6 powders used in this study for additive manufacturing by selective laser melting are supplied by TLS Technik. Table 1 summarizes the technical data.

The test pieces used for this study are of three types:

- cube: dimension $20 \times 20 \times 15 \mathrm{~mm}$;

- tensile (cylinder with 12-mm diameter and 60-mm length): XY plane or vertical (Z axis) (Fig. 1);

- rod (cylinder with 20-mm diameter and 160-mm length), vertical ( $\mathrm{Z}$ axis) (Fig. 1).

\subsection{Heat treatment}

The equipment used for the heat treatment is a forced-air convection oven. This oven is designed for treating aluminum alloys (at temperatures $\leq 650^{\circ} \mathrm{C}$ ) and is characterized by excellent temperature homogeneity $(\Delta \mathrm{T} \leq 6)$.
The quenching fluid is cold water (at approx. $20^{\circ} \mathrm{C}$ ). The transfer time of the load (test pieces) in the quenching medium is less than $7 \mathrm{sec}$ in all cases (SAE AMS2772E standard).

The heat treatments performed on the AlSi7Mg0.6 alloy made by laser melting are as follows:

- soft annealed: from $5 \mathrm{~min}$ to $2 \mathrm{~h}$ at $300^{\circ} \mathrm{C}$;

- artificial aging: from $5 \mathrm{~min}$ to $24 \mathrm{~h}$ at $170^{\circ} \mathrm{C}$;

- T6 temper (solution heat treatment + quenching + artificial aging): $2 \mathrm{~h}$ at $540^{\circ} \mathrm{C}+$ water quenching $+6 \mathrm{~h}$ at $170^{\circ} \mathrm{C}$.

\subsection{Characterization tests}

\section{Porosity}

Porosity measurements use the Archimedes or three weighings method $[2,5]$. This is the method most often used for quickly determining the porosity of parts and test pieces made through additive manufacturing (selective laser melting). Porosity measurements by image analysis are also used on the cube test pieces. These measurements are made with an optical microscope - an Axio Imager M2m (Zeiss).

\section{Hardness}

Brinell hardness measurements are performed at room temperature with an Emco Duramin 500 test machine (EN ISO 6506-1 standard). At least three measurements are performed per test piece (only the average is given).

\section{Tensile tests}

Tensile tests are performed in accordance with the ISO 6892-1 standard with a Zwick Z250 tensile machine $(250 \mathrm{kN})$. The test speed is set to $5 \mathrm{~mm} / \mathrm{min}$.

\section{Micrographic examination and SEM}

Samples for micrographic observation are prepared conventionally (section, coating, polishing, etc.) before observation under an optical microscope - a Zeiss Axio Imager M2m (magnification used from $\times 50$ to $\times 500$ ).

\section{Table 1}

Technical data, powder in AlSi7Mg0.6

\begin{tabular}{|c|c|c|c|c|c|c|c|c|c|c|c|}
\hline Particle size & \multicolumn{11}{|c|}{$\begin{array}{l}\mathrm{D}_{10}=11.7 \mu \mathrm{m} \\
\mathrm{D}_{50}=33.4 \mu \mathrm{m} \\
\mathrm{D}_{90}=62.0 \mu \mathrm{m}\end{array}$} \\
\hline \multirow[t]{2}{*}{ Morphology } & \multicolumn{11}{|c|}{ Spherical type with some satellites } \\
\hline & & Si & $\mathrm{Fe}$ & $\mathrm{Cu}$ & Mn & Mg & $\mathrm{Cr}$ & $\mathbf{N i}$ & $\mathbf{Z n}$ & Ti & $\mathbf{0}$ \\
\hline \multirow[t]{2}{*}{ Chemical composition } & TLS & 6.8 & 0.17 & 0.012 & $<0.005$ & 0.67 & $<0.005$ & 0.01 & 0.008 & 0.18 & 0.047 \\
\hline & EN 1706 & $6.5-7.5$ & $<0.19$ & $<0.05$ & $<0.1$ & $0.45-0.7$ & - & - & $<0.07$ & $<0.25$ & - \\
\hline
\end{tabular}


Two types of etching were used:

- "sulfuric acid" reagent $\left(10 \% \mathrm{H}_{2} \mathrm{SO}_{4}, 5 \% \mathrm{HF}, 85 \%\right.$ distilled water);

- barker reagent (electrolytic etching).

Samples for scanning electron microscopy (SEM) were observed under an SEM - a Zeiss EVD. This is equipped with an energy dispersive X-ray spectroscopy (EDS) sensor.

\section{Electric conductivity measurement}

We use the Foucault currents technique to measure the electric conductivity of non-magnetic metals (which is the case with aluminum alloys).

The instrument used is a Fisherscope MMS pc fitted with an ES40 probe, which is equipped with a thermocouple. The Fisherscope instrument instantly corrects the electric conductivity according to the temperature. We used a frequency of $60 \mathrm{kHz}$ in order to penetrate deep into the alloy.

\section{Residual stress measurements by X-ray diffraction}

The measurements consist of collimating a beam of $\mathrm{X}$-rays with the surface of the test piece and measuring the angle of diffraction with which the rays are returned to the detectors (Bragg's law). The angle of diffraction is directly linked to the distance between the atoms of the material. Compressive stress in the same direction as the link between two atoms reduces the interatomic distance; tensile stress increases the interatomic distance. To analyze the stress in one direction, the "sin $2 \psi$ " technique described in the EN 15305 standard consists of varying the incident beam angle and in monitoring the change of the angle of diffraction. The measurements were made on an Xstress 3000 G2R instrument.

\section{RESULTS AND DISCUSSION}

\subsection{Preliminary}

The manufacturing temperature of the test pieces (manufacturing plate and area) can potentially affect the metallurgical tempers of the AISi7Mg0.6 alloy. Therefore, three manufacturing temperatures were used: 100, 150 (the temperature mainly used), and $200^{\circ} \mathrm{C}$. These temperatures are achievable by the SLM machine: however, temperatures above $200^{\circ} \mathrm{C}$ are not possible with this device. The other manufacturing parameters remained the same.

The porosity of the test pieces can also affect the mechanical properties, hardness, etc. In order to verify that the porosity level of the test pieces used does not significantly influence the results presented, we measured an average porosity level of $0.67 \% \pm 0.20$, which remains within the conventional values of additive manufacturing (laser melting).

\subsection{Mechanical properties}

First, we focused on the mechanical properties obtained with manufacturing at $150^{\circ} \mathrm{C}$ for the following metallurgical tempers (Fig. 2):

- as-built;

- soft annealed: $2 \mathrm{~h}$ at $300^{\circ} \mathrm{C}$;

- T6 (solution heat treatment + quenching + artificial aging);

- artificial aging: $2 \mathrm{~h}$ at $170^{\circ} \mathrm{C}$ and $6 \mathrm{~h}$ at $170^{\circ} \mathrm{C}$.

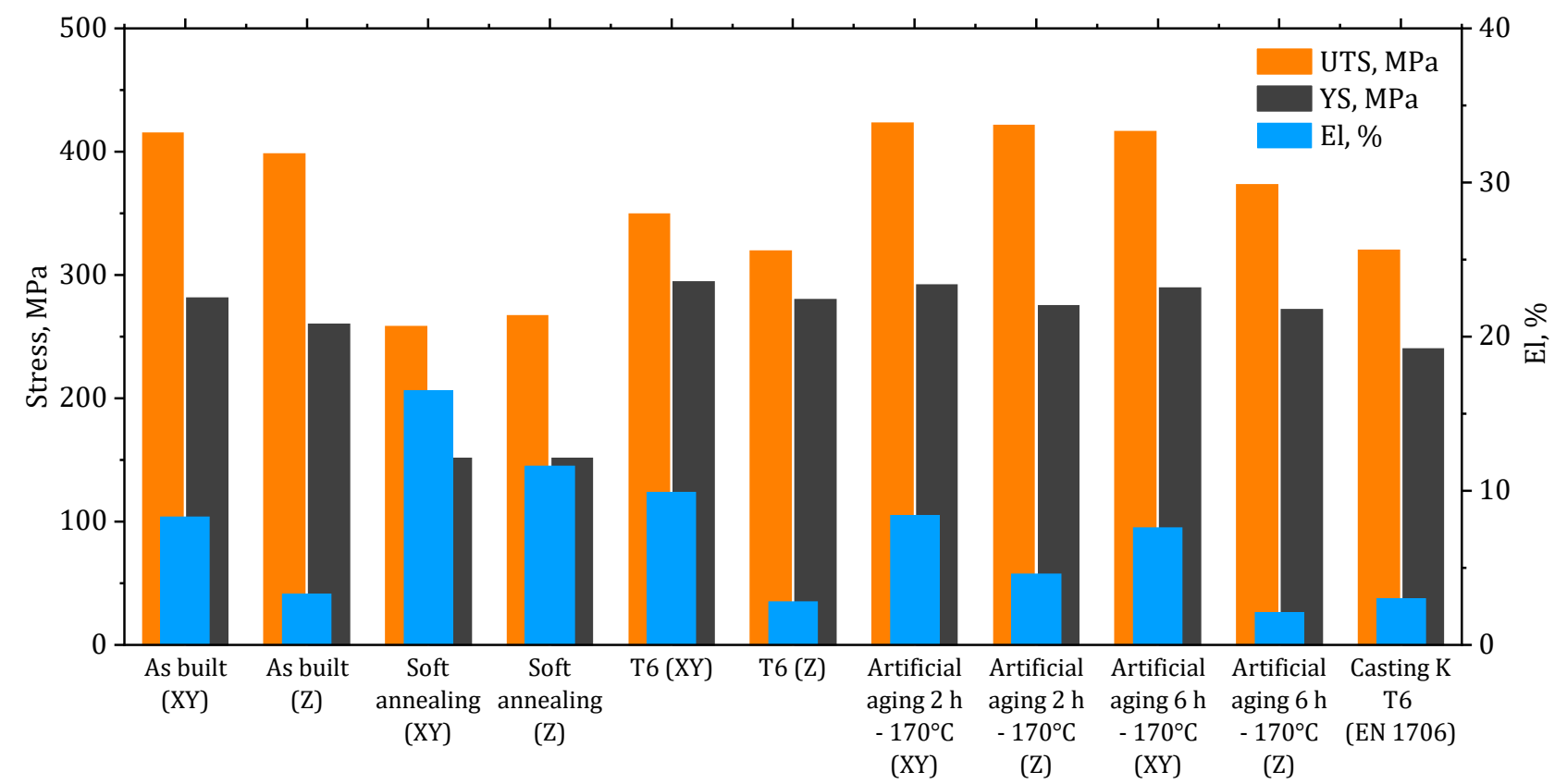

Fig. 2. Mechanical properties (UTS, YS, El) of different metallurgical tempers studied as compared with EN 1706 standard (build at $150^{\circ} \mathrm{C}$ ) 
In Figure 2, we note the following:

- The mechanical properties of the as-built, T6, and artificial aging tempers are greater than the minimums of the EN 1706 standard (K T6). Only those that are soft annealed have mechanical properties lower than the standard, which is not surprising.

- The mechanical properties (UTS, YS \& El) of the as-built and soft annealed are comparable with the data given in the literature [6].

- The T6 temper normally offers the greatest mechanical properties. In the case of additive manufacturing (laser melting), the T6 temper has a high yield stress, but a marked weakening of the UTS is observed (compared with the as-built temper). Furthermore, the elongation remains limited, especially along the $\mathrm{Z}$ axis (barely $3 \%$ ).

- Artificial aging at $170^{\circ} \mathrm{C}$ has the most interesting mechanical properties. In this way, $2 \mathrm{~h}$ artificial aging at $170^{\circ} \mathrm{C}$ offers the best compromise in terms of mechanical properties: UTS is the highest of all the heat treatments, and YS remains very close to the maximum obtained with the T6 temper. It can also be noted that the elongation is correct and clearly higher than the minimum of the EN 1706 standard.

- The purpose of soft annealing is to reduce residual stresses. It is clearly noted that it has the weakest UTS and YS, although its elongation is the greatest.

- A certain anisotropy is observed in the mechanical properties on the $\mathrm{Z}$ axis (this anisotropy is distinct for elongation).

\subsection{As-built}

The structures of aluminum alloys (mainly AlSi10Mg) resulting from selective laser melting have been widely studied in the as-built temper [2, 6-9]. The results of these studies are in agreement with the observations made regarding the AlSi7Mg0.6 alloy:

- Highlight the manufacturing strategy: manufacturing tracks are observed on the XY plane and as well as on the $\mathrm{Z}$ axis of construction (Figs. 3a-b). In addition, we observe a contour strategy at the test piece's edge (Fig. 3a), which is constituted of three contours: the two outermost are the edge contours (first melted), and the inner one is the filling contour used to join the edge contours and the filling. In Figure $3 \mathrm{~b}$ (as well as in Fig. 5a and Fig. 10b), the grains in the tracks are oriented perpendicularly to the tangent of the track edges: the grains develop along paths orthogonal to the isotherms in keeping with the laws of solidification.

- Highlight the microstructure: this is constituted of fine dendrites of solid solution aluminum together with Al-Si eutectics (Figs. 3c-d). The observed fine structure can be explained by the extremely rapid cooling of around $10^{5} \mathrm{C} / \mathrm{s}$ [2]. Also observed is a coarser structure at the track edge due to the heat reassignment of the area [2]. a)

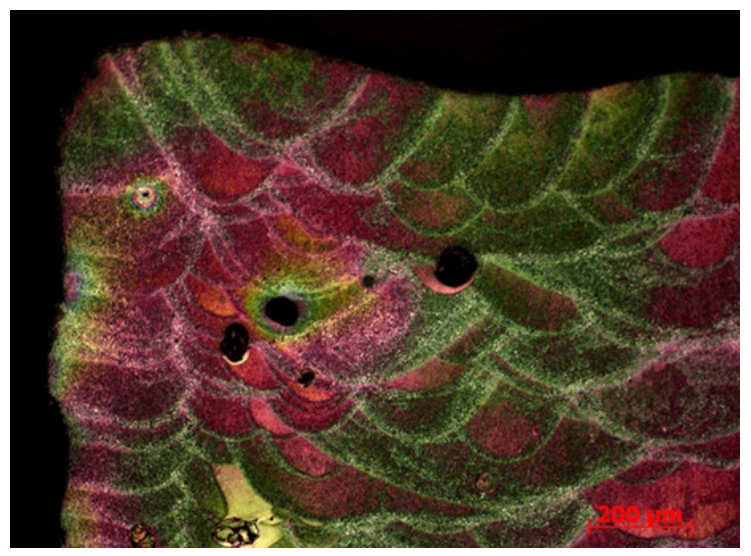

b)

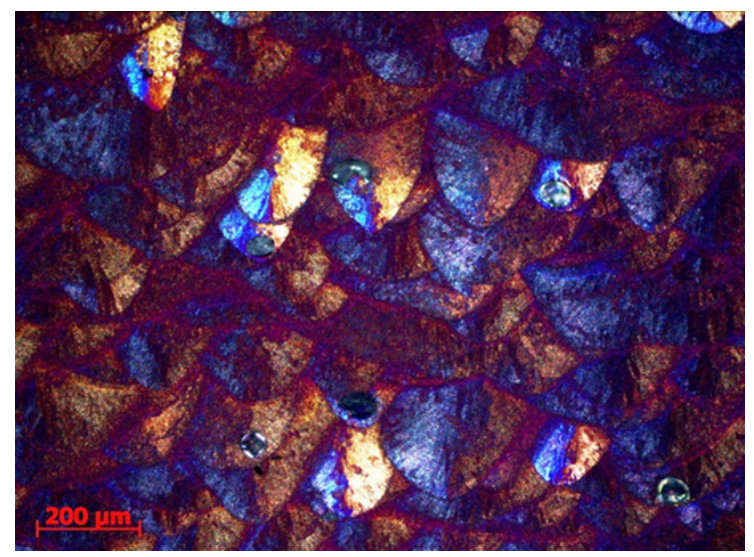

c)

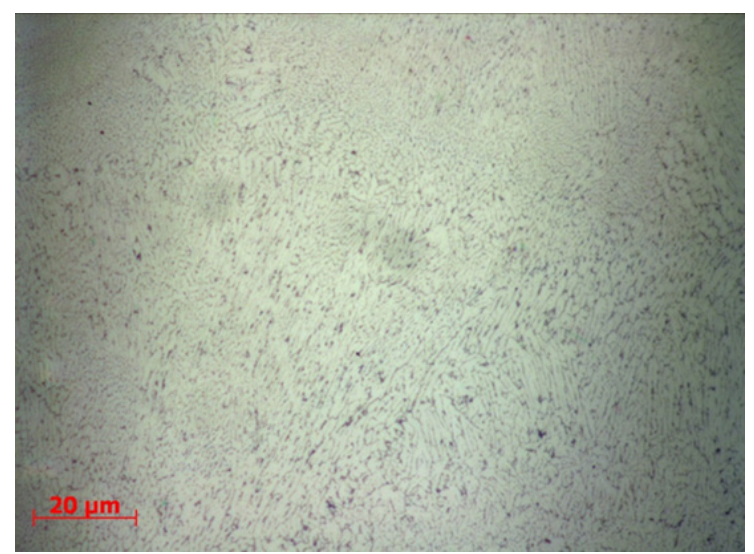

d)

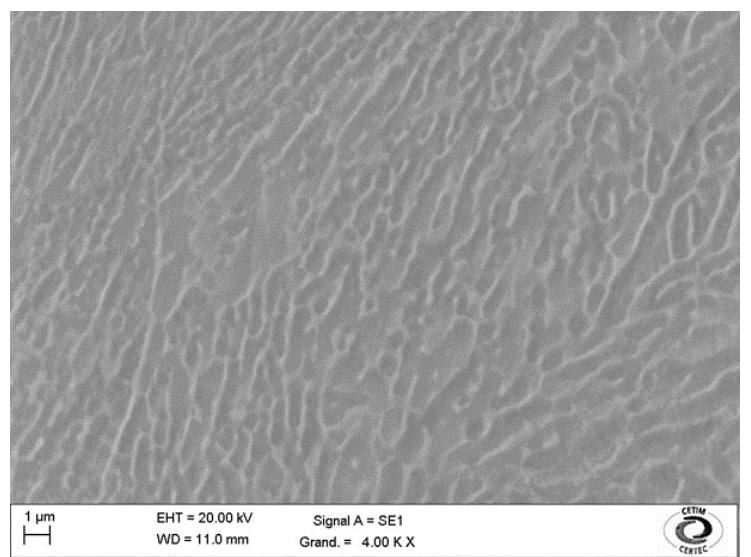

Fig. 3. Micrographic examinations of metallurgical temper studied - As-built: a) and b) strategy of manufacture: beads and grains (optical); c) and d) microstructure (optical and SEM) 
In the literature, there is little mention of the fact that the chemical composition of aluminum alloys and, thus, of AlSi7Mg0.6 can evolve after laser melting. However, certain elements making up the alloy in fact evaporate under the effect of high temperatures (for example, magnesium) [3]. In the present case, we see a loss in magnesium of approx. $25 \%$ by weight.

\subsection{Soft annealing}

This treatment is mainly intended for stress relief in order to relax the residual stresses. We created an isotherm at $300^{\circ} \mathrm{C}$ (from $5 \mathrm{~min}$ to $2 \mathrm{~h}$ ). Figure 4 gives the hardness (HBW 5/250) and electric conductivity results. It can be seen that the hardness decreases with increased treatment time, and the electric conductivity rises. This result is quite standard and perfectly reflects the soft annealing treatment. We note that both hardness and electrical conductivity tend towards an asymptotic limit. The values of hardness and electrical conductivity tend towards those of complete annealing.

The metallurgical structure observed is identical to that of the as-built: manufacturing tracks and the manufacturing strategy can be seen (Fig. 5a). The microstructure is still constituted of fine dendrites of solid solution aluminum together with $\mathrm{Al}-\mathrm{Si}$ eutectics (Fig. 5b). However, fine dendrites are more difficult to observe and become comparatively "blurred" in the as-built temper (as indicated by [6]).

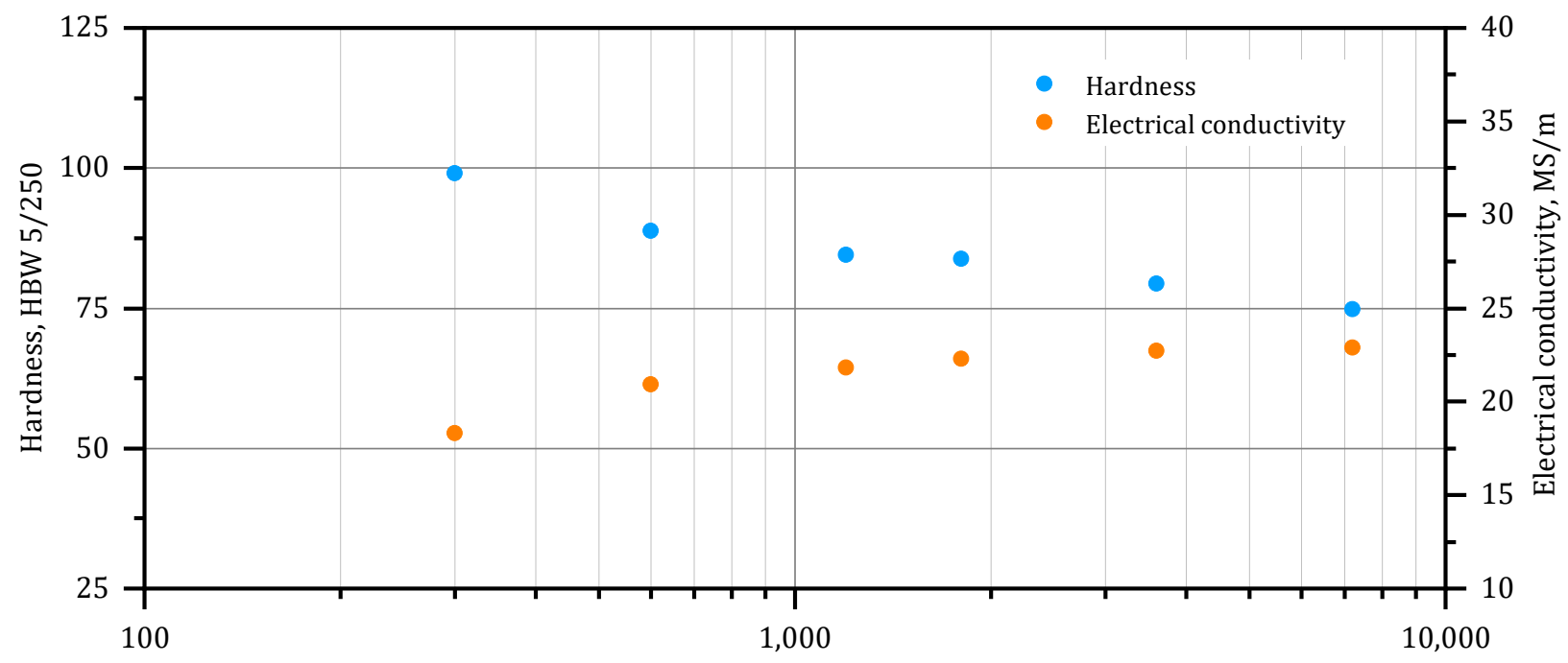

Time, $\mathrm{s}$

Fig. 4. Change in hardness and electric conductivity according to time of soft annealing

a)

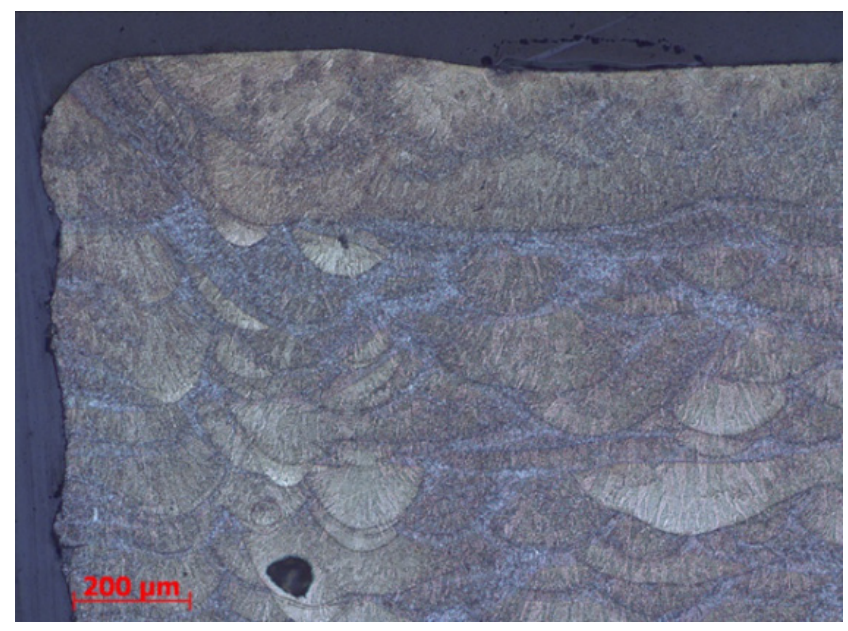

b)

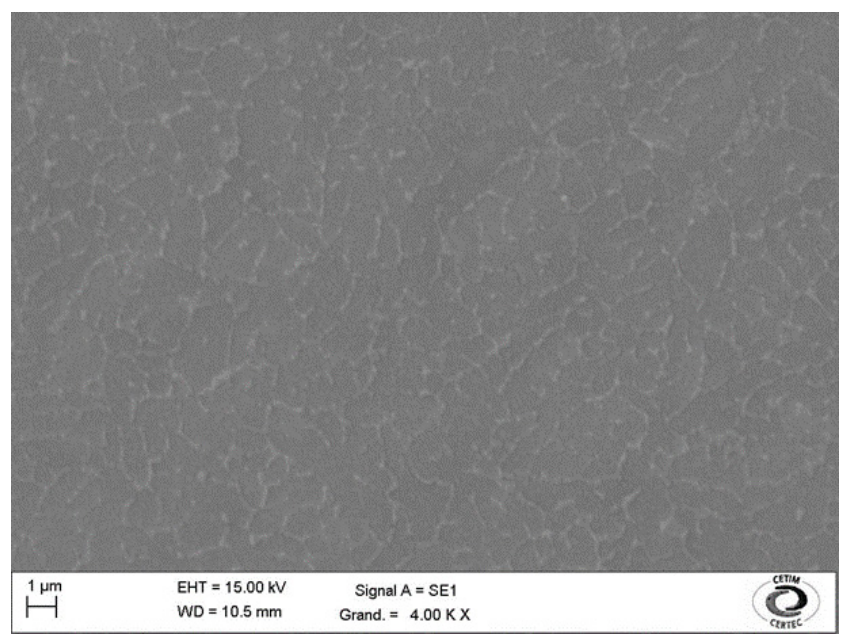

Fig. 5. Micrographic examinations of metallurgical temper studied - soft annealing (S.A.): $2 \mathrm{~h}$ at $300^{\circ} \mathrm{C}$ : a) strategy of manufacture: beads and grains (optical); b) microstructure (optical and SEM) 


\subsection{T6 temper}

The metallurgical structure of the T6 temper is quite different from that of the as-built temper. The manufacturing tracks have disappeared, and the manufacturing strategy can no longer be observed (Fig. 6a). At a higher magnification, Figure $6 \mathrm{~b}$ shows the structure of the $\mathrm{T} 6$ temper, which has changed radically: it is constituted of the aluminum matrix in which small polyhedrons of Si together with fine Al-Fe-Si-type acicular compounds can be observed. Grains (Fig. 6c) that are sometimes underlined by very fine precipitates can just be made out.

a)

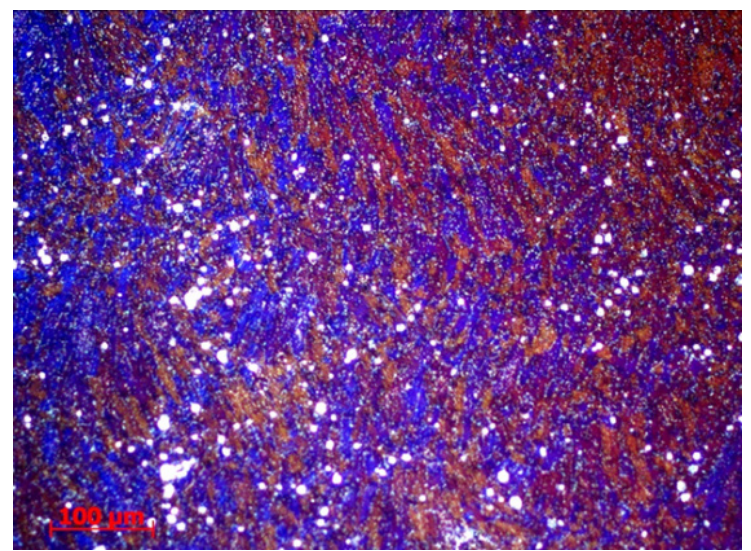

b)

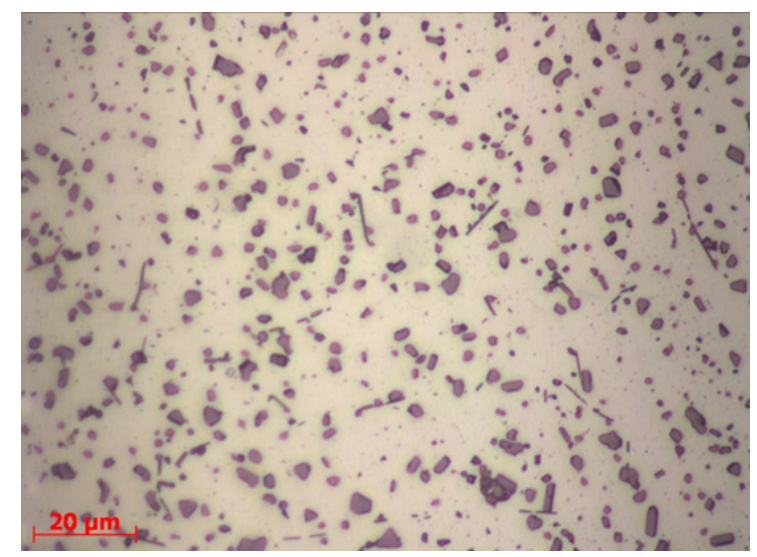

c)

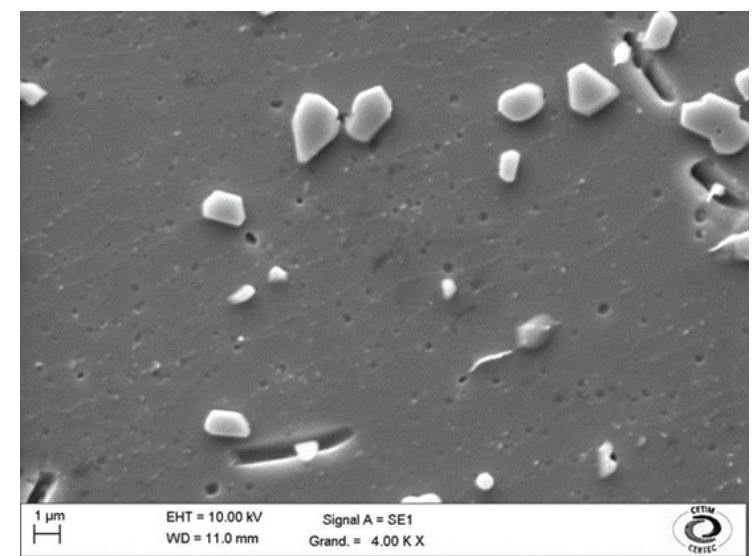

Fig. 6. Micrographic examinations of metallurgical temper studied - T6: a) strategy of manufacture: beads and grains (optical); b) and c) microstructure (optical and SEM)
Rao et al. [10] indicate that the possible origin of the silicon polyhedrons is due to an oversaturation of the solid solution aluminum in the silicon in the as-built temper; this is likely related to the rapid cooling. Thus, the solubility of silicon in the solid solution aluminum exceeds $1.6 \%$ by weight (this value is nevertheless the maximum limit of the solubility in the aluminum at the eutectic temperature), eventually reaching values of approx. $5 \%$ by weight. During the solution heat treatment, the oversaturated solid solution aluminum breaks down, and the solubility of the silicon "naturally" falls below $1.6 \%$ by weight by forming the silicon polyhedrons visible in the T6 (as well as the T4) temper.

Another phenomenon appeared during the solution's heat treatment $\left(2 \mathrm{~h}\right.$ at $\left.540^{\circ} \mathrm{C}\right)$ : the porosity level increased. An increase in the number and size of porosities were seen after the solution heat treatment. This phenomenon is shown outwardly by the appearance of blisters on the surface of the test pieces (Fig. 7). Figure 7 clearly shows a difference in the quantity and size of the porosities before and after the solution heat treatment. The porosity level measured on a micrographic section on the same test piece indicates an increase in porosity; in the as-built temper, the level is $0.43 \%$ - after the solution heat treatment, the level rose to $1.01 \%$.

a)

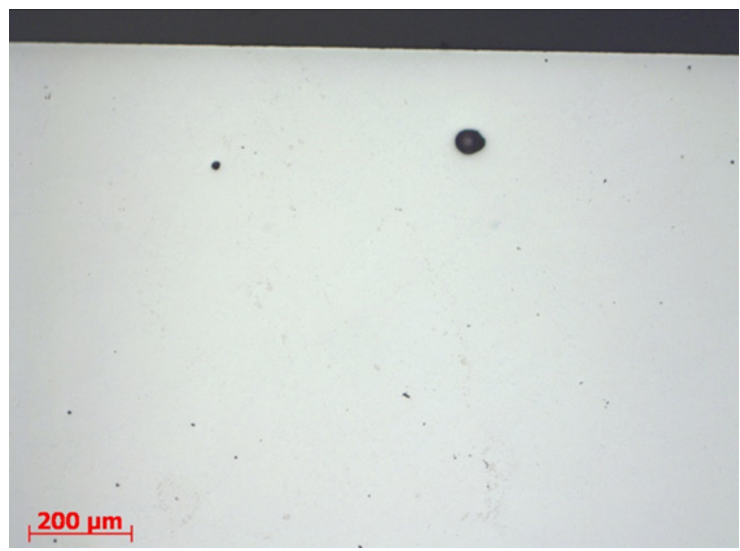

b)

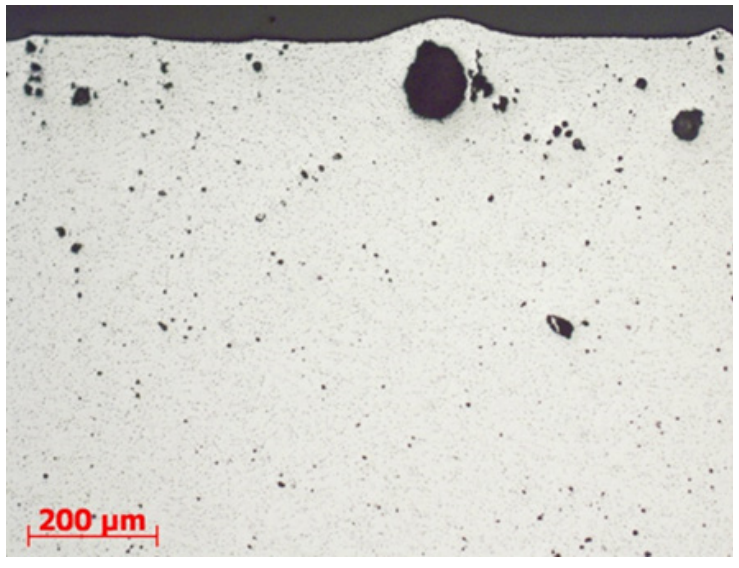

Fig. 7. Change in porosities before and after solution heat treatment: a) as built; b) T6 
In Figure 8, the number of fine porosities after solution treatment "explodes" as compared to the as-built: there are more porosities, and they are larger. These are attributed to the trapped gases (hydrogen) in the molten pool during solidification [11]. During the solution heat treatment, the hydrogen migrates, forming more new porosities (and larger ones at that). This conclusion seems to agree with the analyses of Weingarten et al. [12] on the AlSi10Mg alloy.

\subsection{Artificial aging (alone) - isotherm at $170^{\circ} \mathrm{C}$}

On the as-built temper (with manufacturing carried out at 100,150 , and $200^{\circ} \mathrm{C}$ ), an artificial aging treatment $\left(6 \mathrm{~h}\right.$ at $\left.170^{\circ} \mathrm{C}\right)$ was performed. The mechanical properties obtained are given in Figure 9. There is a decrease in UTS and YS with the manufacturing temperature along with a slight rise in elongation. This can be explained by the fact that the build carried out at $200^{\circ} \mathrm{C}$ passed to over-aging with the treatment of $6 \mathrm{~h}$ at $170^{\circ} \mathrm{C}$. The artificial aging of $6 \mathrm{~h}$ at $170^{\circ} \mathrm{C}$ has the most impact in terms of UTS and YS on the build at $100^{\circ} \mathrm{C}$, which is explained by the fact that the temperature at $100^{\circ} \mathrm{C}$ has no influence on precipitation: the hardening potential is not initiated, and the best mechanical properties are obtained. The build at $150^{\circ} \mathrm{C}$ has good mechanical properties that are slightly weaker than the build at $100^{\circ} \mathrm{C}$. This can be explained in the same way as above: the test pieces passed to slight over-aging.

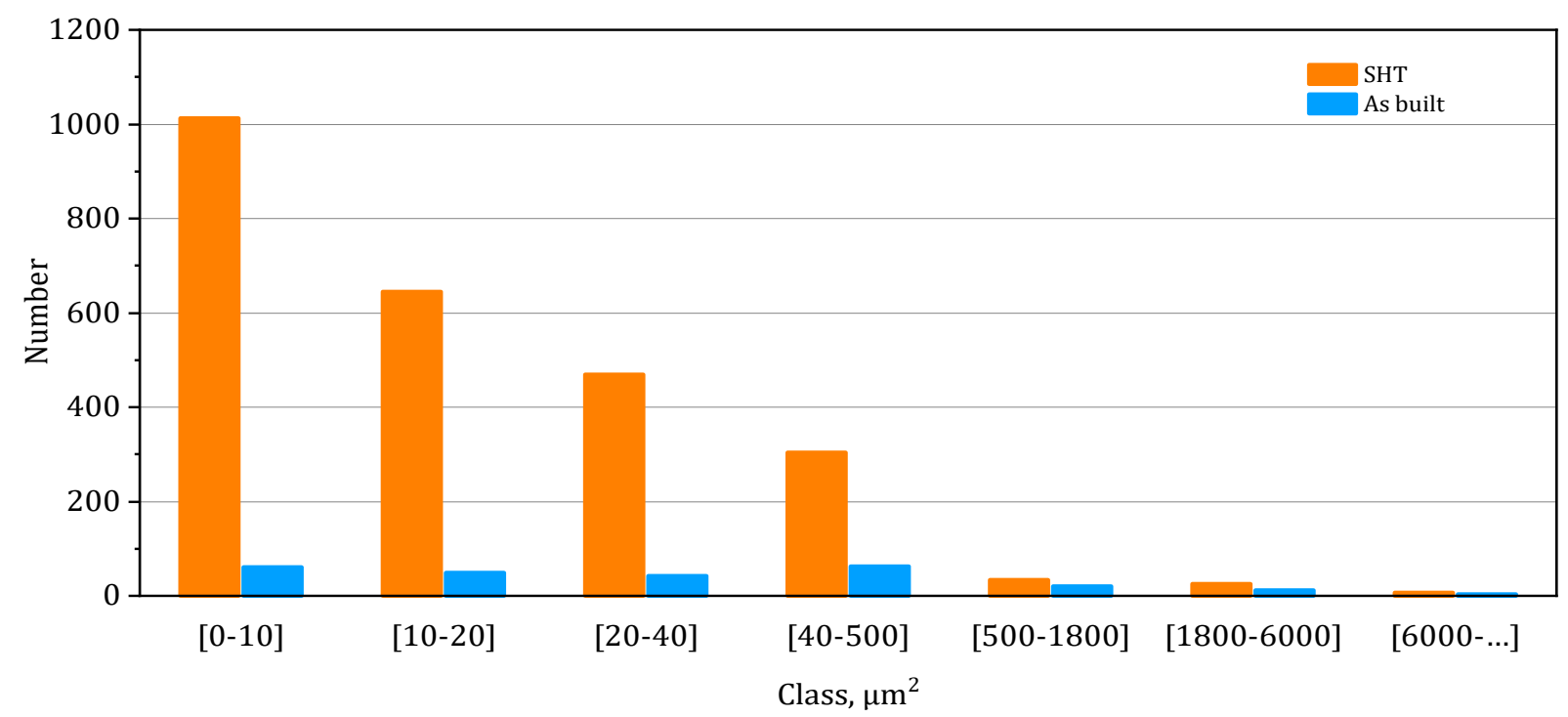

Fig. 8. Distribution of porosities in as-built temper and after solution heat treatment

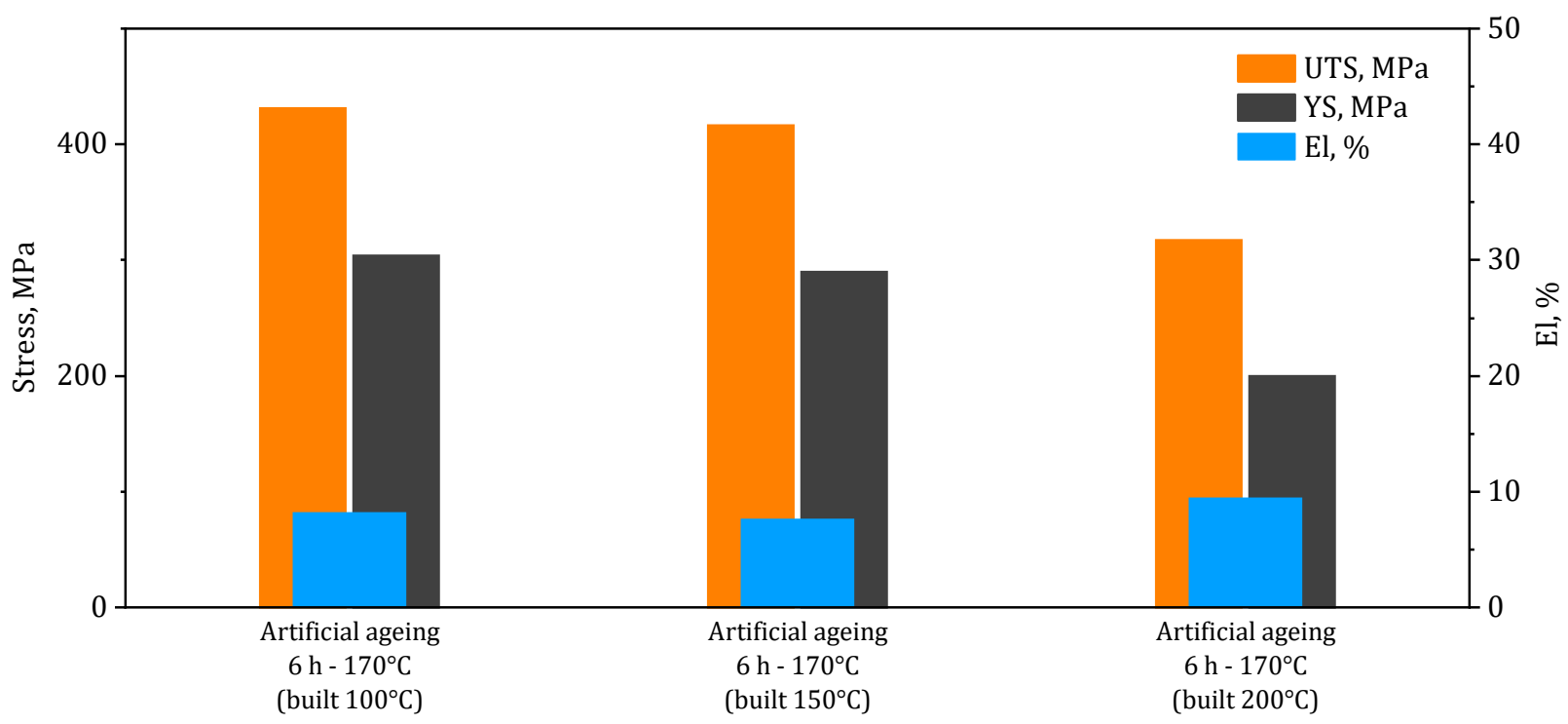

Fig. 9. Conventional mechanical properties (UTS, YS, El) after artificial aging $6 \mathrm{~h}$ at $170^{\circ} \mathrm{C}$ on three builds (at 100,150 , and $200^{\circ} \mathrm{C}$ ) 
The metallurgical structure of the test pieces after artificial aging for $6 \mathrm{~h}$ at $170^{\circ} \mathrm{C}$ (Fig. 10a-c) has not changed when compared with the as-built temper and are comparable to the builds at 100,150 , and $200^{\circ} \mathrm{C}$.

a)

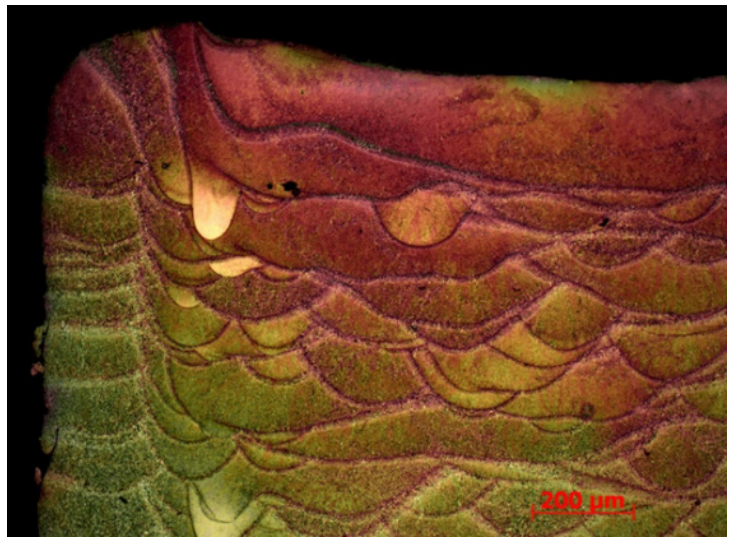

b)

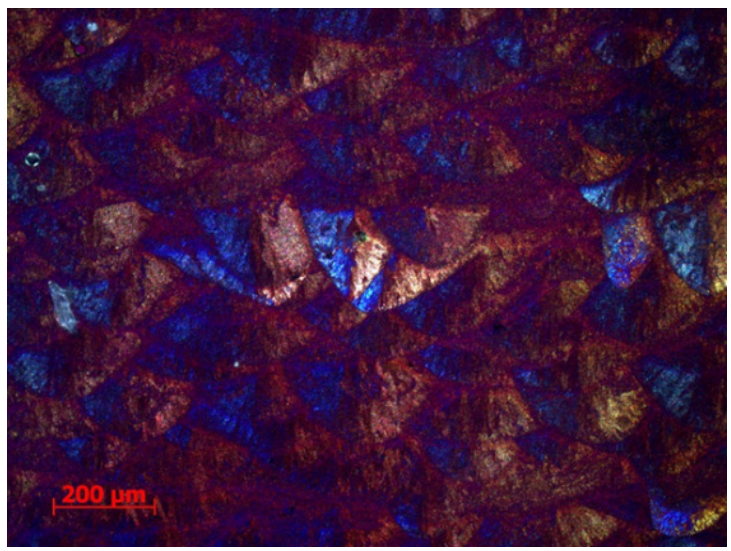

c)

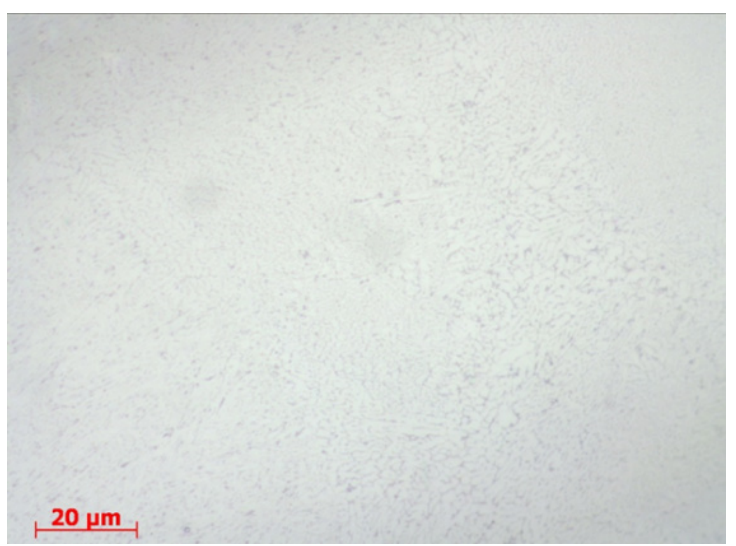

Fig. 10. Micrographic examinations of metallurgical temper studied - artificial aging $6 \mathrm{~h}-170^{\circ} \mathrm{C}$ : a) strategy of manufacture: beads and grains (optical); b) and c) microstructure (optical and SEM)

On the as-built temper at $150^{\circ} \mathrm{C}$, an isotherm at $170^{\circ} \mathrm{C}$ was created ( 5 min to $24 \mathrm{~h}$ ). Figure 11 shows the change in electric conductivity and hardness according to the exposure time to $170^{\circ} \mathrm{C}$. It can be seen that the electric conductivity increases and hardness reaches a peak at approximately $3 \mathrm{~h}$ of exposure. Thus, the maximum mechanical properties would be reached in artificial aging at approx. $3 \mathrm{~h}$.

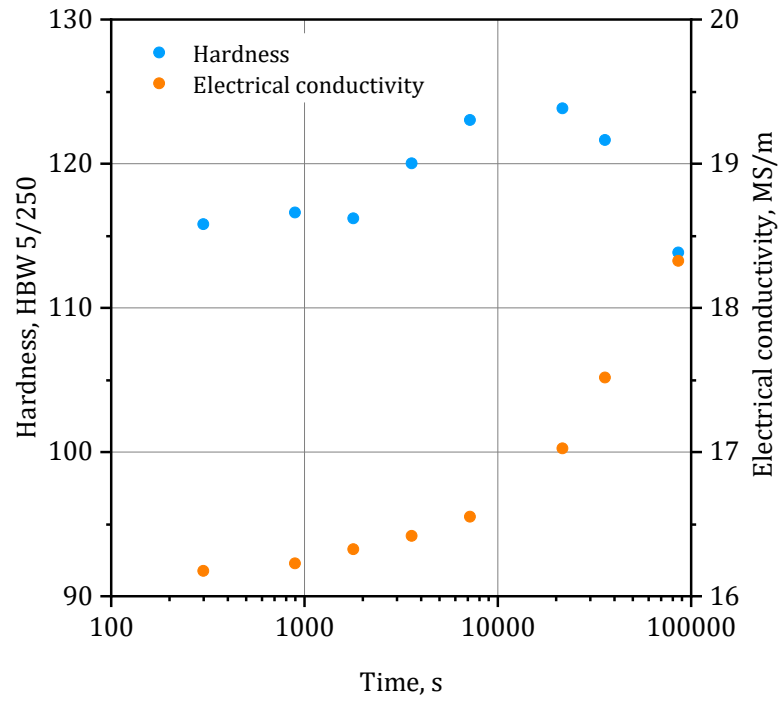

Fig. 11. Changes in hardness and electric conductivity according to artificial aging time at $170^{\circ} \mathrm{C}$

Among the experimental methods to study the structural precipitation of aluminum alloys are macroscopic physical methods; these use macroscopic variations of an alloy's physical properties (electrical, thermal, dimensional, etc.) according to its state of precipitation. Electric conductivity (and conversely electric resistivity) are governed by the state of the breakdown of the solid solution of the aluminum alloy studied [13].

The isothermal transformation kinetics that proceed by germination and growth are often described by the Johnson-Mehl-Avrami-Kolmogorov (JMAK) model, which assumes random germination and uniform growth. The JMAK model is based on the concept of "extended volume," which is the volume that a new nucleus would occupy in the absence of the encroachment or overlapping of an already transformed adjacent nucleus [14].

$$
x(t)=1-\exp \left(-[k(T) t]^{n}\right)(\text { JMAK model })
$$

where:

$$
\begin{aligned}
x(t) & - \text { the transformed volume fraction; } \\
n & - \text { called the Avrami exponent, which is an indica- } \\
& \text { tion of the transformation mechanism; } \\
t & - \text { the isothermal hold time; } \\
k(T) & - \text { a speed constant essentially dependent on the } \\
& \text { temperature. }
\end{aligned}
$$

And so $k(T)$ can be expressed by an Arrhenius equation:

$$
k(T)=k_{0} \exp \left(-\frac{E_{a}}{\mathrm{R} T}\right)
$$

where:

$E_{a} \quad$ _ the activation energy for isothermal germination and growth;

$k_{0}-$ a constant. 
As shown above, the electric conductivity is governed by the state of the breakdown of the solid solution (of the aluminum alloys) and, thus by the transformation kinetics (precipitation and dissolution of the precipitates).

Thus, the volume fraction $x(t)$ transformed in an isothermal reaction can be described as follows:

$$
x(t)=\frac{\sigma(t)-\sigma_{0}}{\sigma_{f}-\sigma_{0}}
$$

where:

$$
\begin{aligned}
x(t) & - \text { volume fraction transformed in time } t \text { (isother- } \\
& \text { mal transformation; } \\
\sigma(t) & - \text { electric conductivity in time } t \\
\sigma_{o} & - \text { initial electric conductivity; } \\
\sigma_{f}- & \text { final electric conductivity. }
\end{aligned}
$$

The JMAK model can be applied to the previous results. The volume fraction transformed in time $t: x(t)$ can be obtained from the measurements of electric conductivity given above. Then, it is possible to determine the parameters of the JMAK model from the previous equations as follows:

$$
\log \left(\ln \left(\frac{1}{1-x(t)}\right)\right)=n \log (t)+n \log (k(T))
$$

then, it is a matter of plotting $\left(\ln \left(\frac{1}{1-x(t)}\right)\right)$ according to $\log (t)$. If the model applies, a straight line should be obtained (possibly one straight line per portion). In this case, $n$ (the Avrami exponent) is the slope of the straight line, and $n \log (k(T))$ is the ordinate at the origin. We obtain $n$ and $k(T)$ (Fig. 12); thus, $n=1.19$ and $k(T)=3.2310^{4}$. As shown previously $n$, is called the Avrami exponent, which supplies an indication of the transformation mechanism. Here $n$, is close to 1 , so it involves needle thickening [15]. According to the literature [16], we have precipitation of the phase $\beta^{\prime \prime}$ (as fine needles), then $\beta^{\prime}$ (as needles then rods), and finally $\beta$ as plates or laths. Thus, the value of $n$ (close to 1) can transcribe the precipitation of $\beta^{\prime \prime}$ and $\beta^{\prime}$ as far as needle thickening, which can be similar to rods. This is confirmed by Figure 11, where peak hardness (and thus the peak of the mechanical properties) is obtained by the precipitation of $\beta^{\prime \prime}$ and $\beta$ '.

\subsection{Build height}

We measured the hardness on cylindrical test pieces with a height of $160 \mathrm{~mm}$. These test pieces were manufactured at 100,150 , and $200^{\circ} \mathrm{C}$. We compared the results obtained (Fig. 13). It should be recalled that the rapid cooling (around $10^{5}{ }^{\circ} \mathrm{C} / \mathrm{s}$ ) during manufacture causes a quench effect on the test pieces.

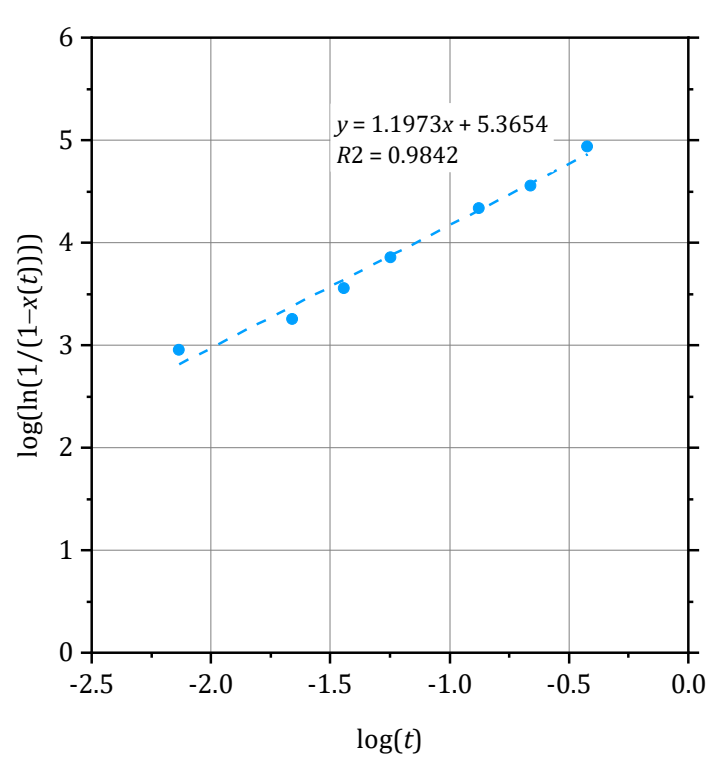

Fig. 12. Application of JMAK model on electric conductivity

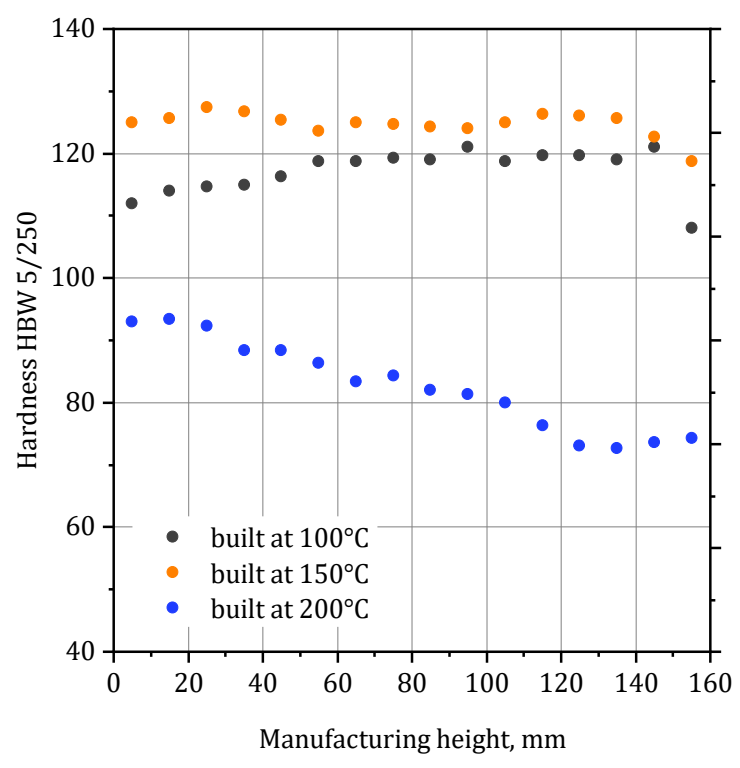

Fig. 13. Hardness tests carried out on height of test pieces manufactured at 100,150 , and $200^{\circ} \mathrm{C}$

Figure 13 leads us to these reflections:

- The build at $200^{\circ} \mathrm{C}$ has the lowest hardness because the manufacturing temperature at $200^{\circ} \mathrm{C}$ necessarily means the mechanical properties are reduced by the over-aging effect (the standard artificial aging for this alloy is $6 \mathrm{~h}$ at $170^{\circ} \mathrm{C}$ ). The reduction in hardness with build height can have several origins: a lower cooling speed (hence, a coarser structure) and greater difficulty to evacuate heat on the powder-bed (hence, a higher manufacturing temperature, which means greater over-aging). 
- The slight increase in hardness for the build at $100^{\circ} \mathrm{C}$ (approx. 112 to 121 HBW 5/250) is explained in the same way as above; i.e., it is undoubtedly harder for the heat to be evacuated, which increases the manufacturing temperature with the build height. Thus, the start of artificial aging appears (under-aging). The final drop in hardness is explained by a temper close to maturation (T4 temper).

- For the build at $150^{\circ} \mathrm{C}$, the stability of the hardness values can also be explained by this effect of the temperature increase with the build height. Artificial aging (certainly longer for lower builds) is carried out at $150^{\circ} \mathrm{C}$ (manufacturing temperature), and the artificial aging for the higher builds (certainly shorter) is carried out at higher temperatures (a rise in temperatures with the height of the build).

On these same as-built test pieces, we applied different heat treatments:

- solution heat treatment + quenching + artificial aging: T6 temper,

- $\operatorname{artificial}$ aging $\left(6 \mathrm{~h}\right.$ at $\left.170^{\circ} \mathrm{C}\right)$.

We then proceeded with new hardness measurements that we compared with the as-built value and found the following (Fig. 14):

- the T6 temper enables the hardness values to stabilize over the whole build height, and the same hardness to be obtained whatever the manufacturing temperature;

- artificial aging $\left(6 \mathrm{~h}\right.$ at $\left.170^{\circ} \mathrm{C}\right)$ enables the hardness values to stabilize for the builds made at $100^{\circ}$ and $150^{\circ} \mathrm{C}$; this is explained by the fact that the manufacturing temperatures are below the artificial aging temperature and that a precipitation potential remains (which is not the case for $200^{\circ} \mathrm{C}$ ).

\subsection{Residual stresses}

Residual stresses are internal stresses present at equilibrium in a mechanical part. The state of the residual stresses in the part is the result of the entire manufacturing scheme (the processes). During the manufacture of the part, uncontrolled relaxation of the residual stresses can cause detrimental deformations. After being put into service, any residual stresses present at the end of manufacturing are added to the external mechanical stresses. As a result, they affect the part's lifetime. In general, residual compression stresses at the surface are beneficial and cause an increase of resistance to fatigue or to corrosion under stress. Tensile residual stresses are penalizing and correspond to areas at risk of premature failure.

The test pieces used for the study of residual stresses are cylinders with a diameter of $12 \mathrm{~mm}$ and length of $60 \mathrm{~mm}$ (attached or detached from the manufacturing plate).

The studied test pieces in the AlSi7Mg0.6 aluminum alloy are given below:

- as-built attached to the plate and detached from the plate;

- solution heat treatment $\left(2 \mathrm{~h}\right.$ at $\left.540^{\circ} \mathrm{C}\right)+$ quenching (in water $)+\operatorname{artificial}$ aging $\left(6 \mathrm{~h}\right.$ at $\left.170^{\circ} \mathrm{C}\right)$ attached to the plate and detached from the plate;

- artificial aging $\left(6 \mathrm{~h}\right.$ at $\left.170^{\circ} \mathrm{C}\right)$ attached to the plate and detached from the plate.

The measurements are taken as follows in the same way on each test piece (Fig. 15):

- one area in the middle of the test piece;

- one area $7 \mathrm{~mm}$ from the end: edge (1 or 2);

- one end area ( 1 or 2 ).

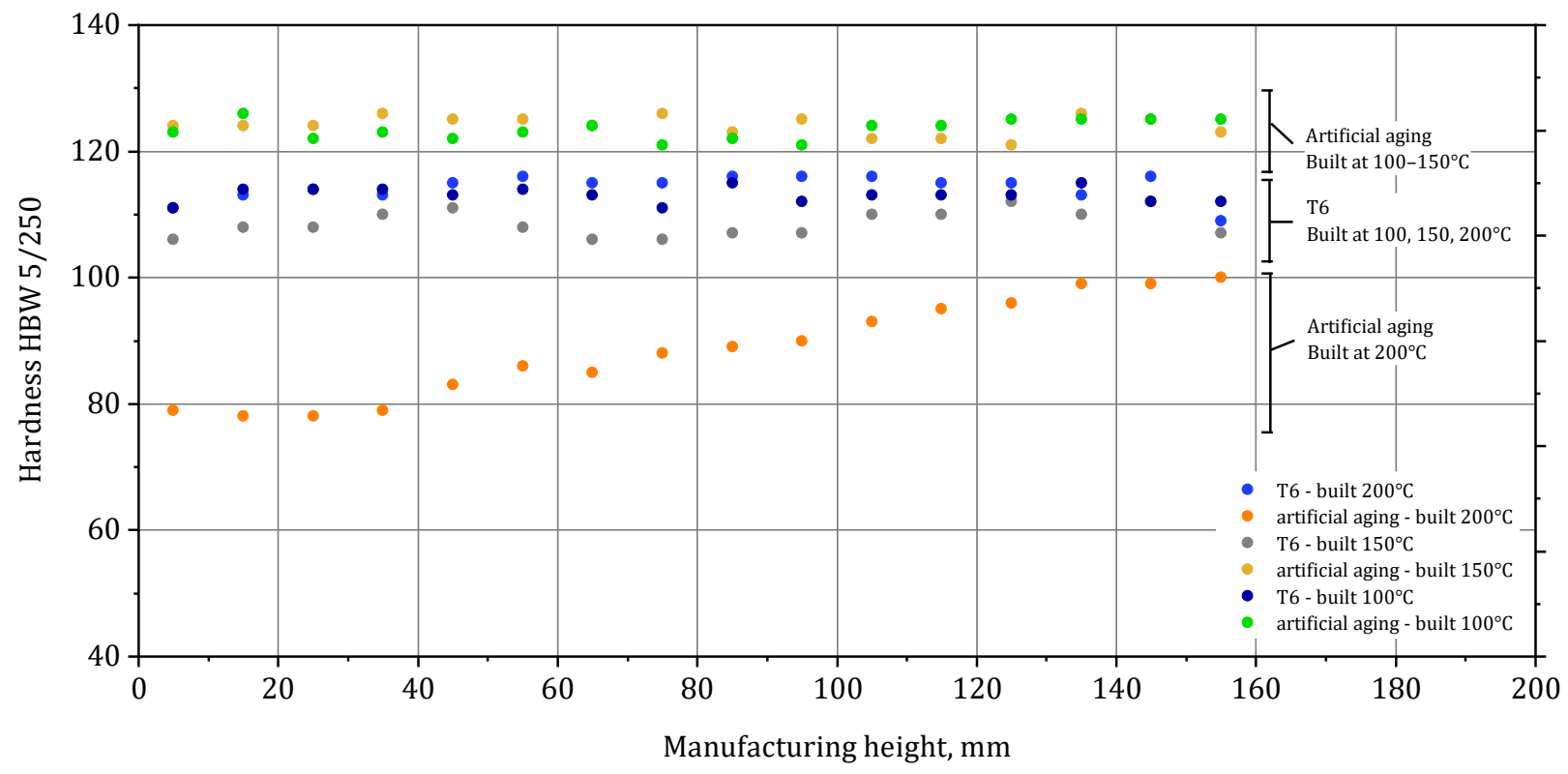

Fig. 14. Change in hardness with build height $\left(100,150\right.$, and $\left.200^{\circ} \mathrm{C}\right)$ according to heat treatment (T6 and artificial aging) 

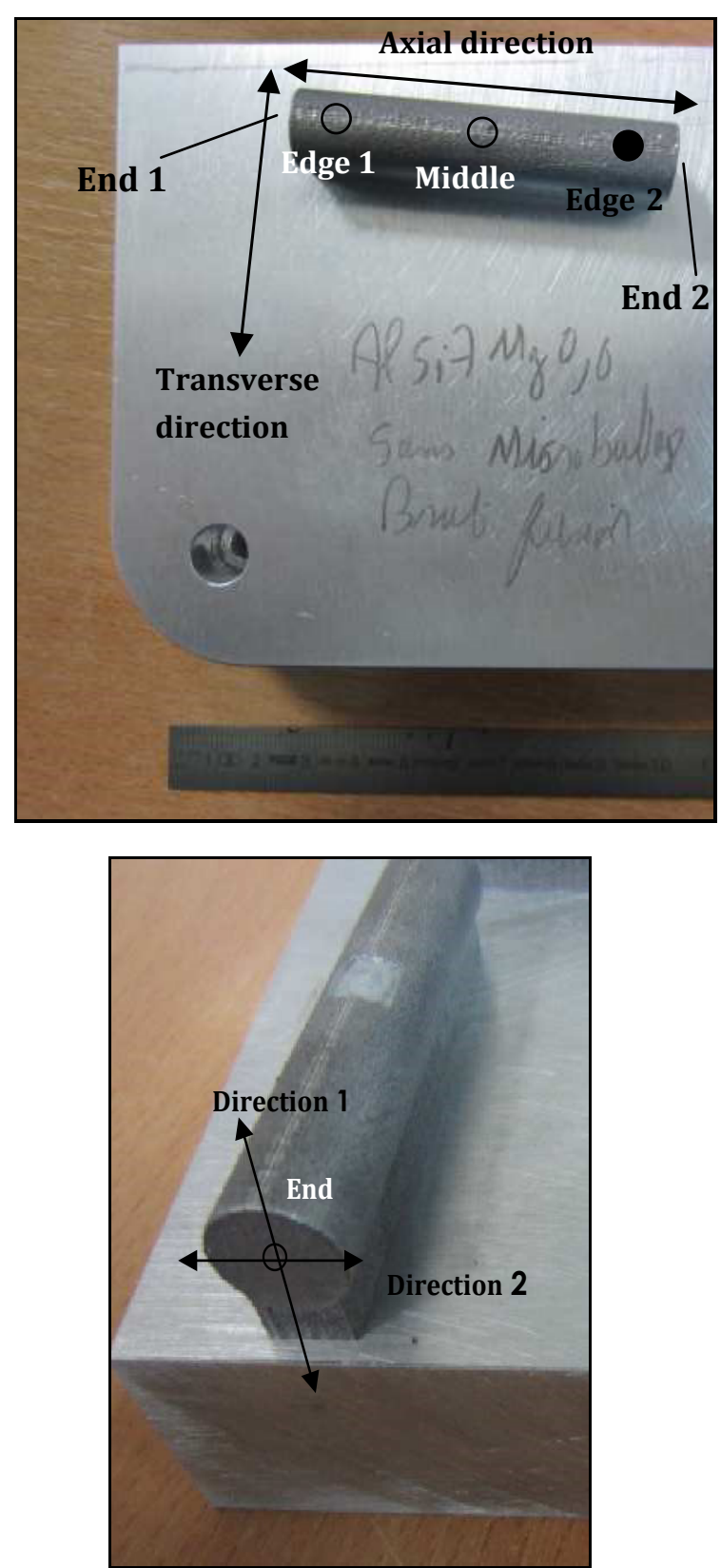

Fig. 15. Illustration of measurement areas and directions analyzed

For each area, the residual stresses are measured (Fig. 15):

- at $850 \mu \mathrm{m}$ deep;

- in the axial and crosswise directions for the "edge" and "middle" areas;

- in Directions 1 and 2 for the "end" areas.

Note that the measurement uncertainty is estimated at $\pm 3 \%$ for the depths as well as for residual stresses at $\pm 30 \mathrm{MPa}$.

The "as-built attached to the plate" test piece has the greatest residual stresses - between 120 and $160 \mathrm{MPa}$ (as per area) - except for the end in Direction 2, where the stresses are weaker (at around $25 \mathrm{MPa}$ ). The greatest stresses are obtained at the edge (Fig. 16). a)

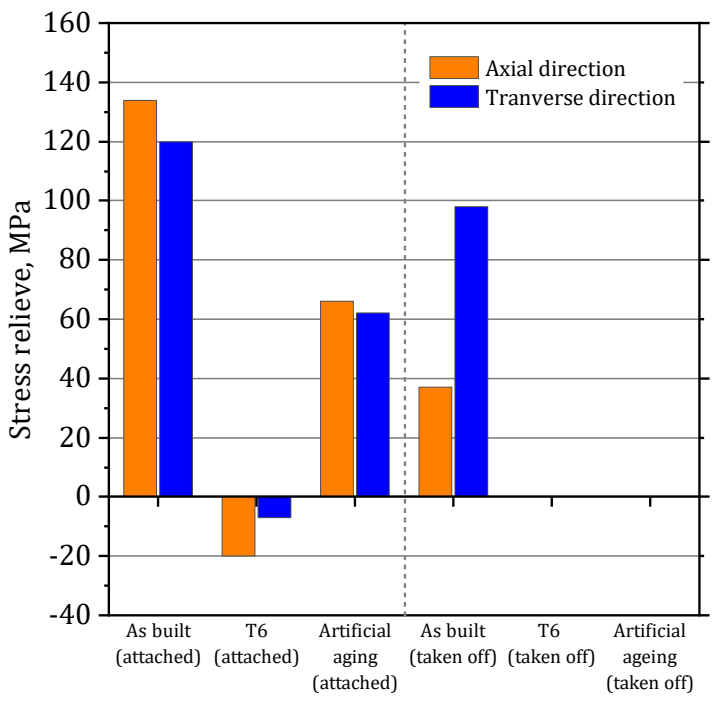

b)

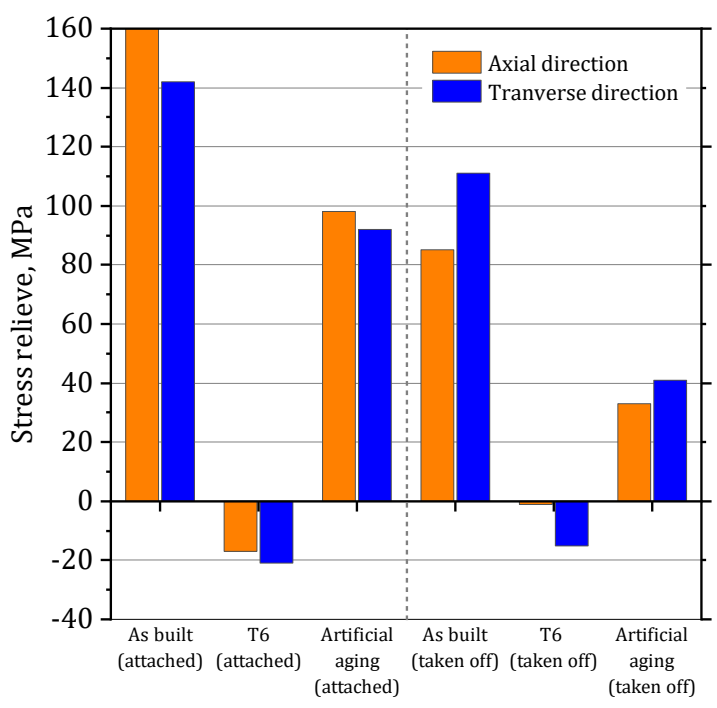

c)

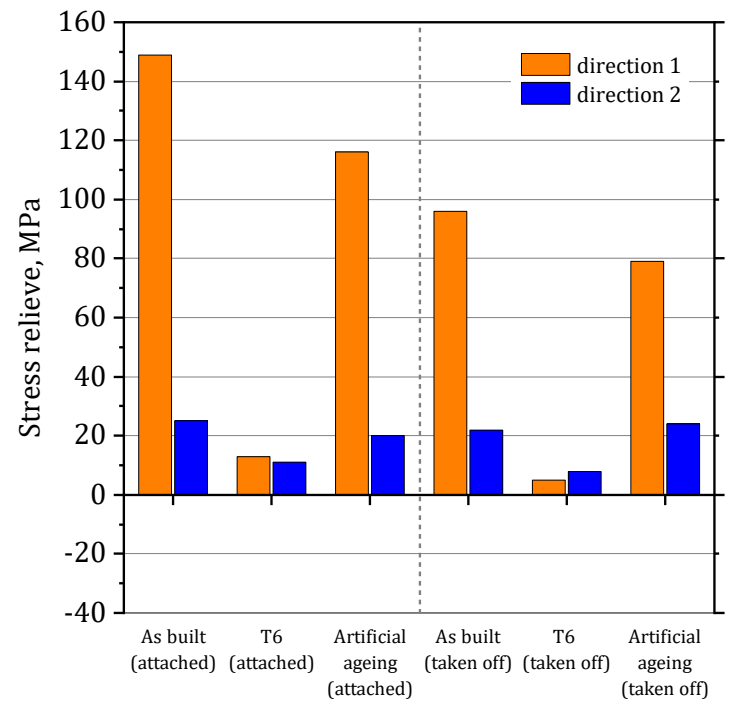

Fig. 16. Change in residual stresses according to measurement location, heat treatment, and whether or not test piece was attached to manufacturing plate: a) middle; b) edge; c) end 
The "as-built detached from the plate" test piece has weaker residual stresses than the previous test piece these are between 20 and $110 \mathrm{MPa}$. Note that the greatest stresses are obtained at the edge and the weakest at the end in Direction 2. Compared with the "as-built attached to the plate" test piece, the stresses reduced by approx. 30 to $75 \mathrm{MPa}$. Also note that, in the crosswise directions, the stresses are less relaxed by cutting and not at all in the case of Direction 2 (Fig. 16).

The "T6 attached to the plate" test piece has the weakest stresses and sometimes in slight compression (between 10 and -25 MPa). The same test piece detached from the plate shows an almost identical profile. Note that the residual stresses measured in the different areas are more homogeneous (tighter values). The test pieces from this temper have the weakest tensile residual stresses (Fig. 16).

The "artificially aged attached to the plate" test piece has residual stresses weaker than the "as-built attached to the plate" test piece but higher than the "T6 attached to the plate" test piece - these are between 20 and $120 \mathrm{MPa}$. The measurements carried out after detaching from the plate show a reduction of approx. $50 \mathrm{MPa}$ of the level of residual stresses. Note again that the stresses are less relaxed in the crosswise direction and not at all in Direction 2 (Fig. 16).
It can be seen that:

- The residual stresses are very often highest at the edge and lowest at the end in Direction 2, which seems logical given the shape of the test piece.

- There is a relaxation of the residual stresses of around $50 \mathrm{MPa}$ when the test piece is detached from the plate.

- The more "vigorous" the heat treatment, the more relaxed the stresses. The temper obtained after T6 even has stresses in slight compression.

\section{CONCLUSIONS}

To demonstrate some originality, the conclusion lists the advantages and disadvantages (seen in this analysis) of the different metallurgical tempers studied previously: this enables a practical link with possible industrial applications (Tab. 2).

\section{Acknowledgments}

The authors would like to thank all of the partners of the SUPCHAD (Supply Chain for Aeronautics and Defense) program - Cetim, Safran Electronics \& Defense, Zodiac Aerospace, MBDA, ThyssenKrupp, Roxel, Mkair, and Mecabess - for the help provided in carrying out this study.

Table 2

Advantages and disadvantages of different metallurgical tempers studied

\begin{tabular}{lll}
\hline \multicolumn{1}{c}{ Advantages } & \multicolumn{1}{c}{ Disadvantages } \\
\hline As-built & - $\begin{array}{l}\text { Anisotropy in mechanical properties. } \\
\text { Considerable residual stresses. }\end{array}$ \\
& $\begin{array}{l}\text { No heat treatment; hence, quicker and less ex- } \\
\text { pensive. } \\
\text { Useful mechanical properties. }\end{array}$ & $\begin{array}{l}\text { Possility of change in mechanical properties } \\
\text { with build's height. } \\
\text { Influence of manufacturing temperature on me- } \\
\text { chanical properties. }\end{array}$ \\
\end{tabular}

Soft annealing

- No (or few) residual stresses.

- Isotropic mechanical properties.

- More homogenous structure.

- No influence of manufacturing temperature.
- Weak mechanical properties.

- Cost of heat treatment.

- Increase and enlargement of porosities.

- Risk of deformation on quenching.

- No anisotropy.

- No influence of manufacturing temperature on mechanical properties.

\section{Artificial aging} ( $6 \mathrm{~h}$ at $\left.170^{\circ} \mathrm{C}\right)$
- Good mechanical properties: best for UTS - close to T6 temper for YS.

- Some facility of heat treatment.

- Optimization of artificial aging $3 \mathrm{~h}$ at $170^{\circ} \mathrm{C}$
- Residual stresses.

- Anisotropy in mechanical properties.

- Influence of manufacturing temperature on mechanical properties. 


\section{REFERENCES}

[1] Pillot S. (2016). Fusion laser sélective de lit de poudres métalliques. Technique de l'ingénieur BM7900.

[2] Mauduit A., Pillot S. \& Frascati F. (2015). Application study of AlSi10Mg alloy by selective laser melting: physical and mechanical properties, microstructure, heat treatments and manufacturing of aluminium metallic matrix composite (MMC). Metallurgical research \& technology, 112, 605. Doi:10.1051/ metal/2015039.

[3] Mauduit A., Pillot S. \& Gransac H. (2017). Study of the suitability of aluminum alloys for additive manufacturing by laser powder-bed fusion. U.P.B. Scientific Bulletin series B, 79(4), 219-238,

[4] Rao H., Giet S., Yang K., Wu X. \& Davies C.H.J. (2016). The influence of processing parameters on aluminium alloy A357 manufactured by selective laser melting. Materials \& Design, 109, 334-346. Doi: 10.1016/j.matdes.2016.07.009.

[5] Spierings A.B., Schneider M. \& Eggenberger R. (2011). Comparison of density measurement techniques for additive manufactured metallic parts. Rapid Prototyping Journal, 17(5), 380-386. Doi: 10.1108/13552541111156504.

[6] Trevisan F., Calignano F., Lorusso M. \& Ambrosio E.P. (2016). Effects of heat treatments on A357 alloy produced by selective laser melting. World PM2016 - Oral session.

[7] Brandl E., Heckenberger U., Holzinger V. \& Buchbinder D. (2011). Additive manufactured AlSi10Mg samples using Selective Laser Melting (SLM): Microstructure, high cycle fatigue, and fracture behavior. Materials \& Design, 34, 159-169. Doi:10.1016/j.matdes.2011.07.067.
[8] Kempen K., Thijs L., Van Humbeeck J. \& Kruth J.P. (2012). Mechanical properties of AlSi10Mg produced by selective laser melting. Physics Procedia, 39, 439-446.

[9] Manfredi D., Calignano F., Krishnan M., Canali R., Ambrosio E.P. \& Atzeni E. (2013). From powders to dense metal parts: characterization of a commercial AlSi10Mg alloy processed through direct metal laser sintering. Materials, 6, 856-869. Doi: $10.3390 / \mathrm{ma} 6030856$.

[10] Rao J.H., Zhang Y., Fang X., Chen Y., Wu X. \& Davies C.H.J. (2017). The origins for the tensile properties of selective laser melted aluminium alloy A357. Additive Manufacturing, 17, 113-122. Doi: 10.1016/j.addma.2017.08.007.

[11] Aboulkhair N.T., Everitt N.M., Ashcroft I. \& Tuck C. (2014). Reducing porosity in AlSi10Mg parts processed by selective laser melting. Additive Manufacturing, 1(4), 77-86. Doi:10.1016/ j.addma.2014.08.001.

[12] Weingarten C., Buchbinder D., Pirch N., Meiners W., Wissenbach K. \& Poprawe R. (2015). Formation and reduction of hydrogen porosity during selective laser melting of AlSi10Mg. Journal of Materials Processing Technology, 221, 112-120. Doi: 101016/j.matprotec.2015.02.013.

[13] Dubost B. \& Sainfort P. (1991). Durcissement par précipitation des alliages d'aluminium. Technique de l'ingénieur M240v1.

[14] Yan J. (2006). Strength modelling of Al-Cu-Mg type alloys. Doctoral Thesis, University of Southampton. Faculty of Engineering Science \& Mathematics.

[15] Appolaire B. Croissance/Dissolution, cours théorique de l'INPL.

[16] Fang X., Song M., Li K. \& Du Y. (2010). Precipitation sequence of an aged Al-Mg-Si alloy. Journal of Mining and Metallurgy. Section B: Metallurgy, 46(2), 171-180. Doi: 10.2298/jmmb1002171f. 